\title{
Striking rash in a patient with lung cancer on a checkpoint inhibitor
}

\author{
Georges E Tanios, MD, ${ }^{\text {ab }}$ David G Morrison, $\mathrm{MD}, \mathrm{PhD},{ }^{\mathrm{a}}$ and Reinhold Munker, $\mathrm{MD}^{\mathrm{ab}}$
}

${ }^{a}$ Section of Hematology and Medical Oncology, Department of Medicine, Tulane University, and ${ }^{b}$ University Medical Center, both in New Orleans, Louisiana

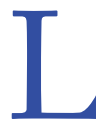

ung cancer remains the most common cause of cancer death in the United States and worldwide. ${ }^{1}$ Despite advances in the treatment of the disease and development of targeted therapy, the 5-year overall survival in stage IV nonsmall-cell lung cancer remains poor, ranging from $6 \%$ to $10 \%$. $^{2}$ More recently, checkpoint inhibitors have had a major impact on the treatment of lung cancer. Nivolumab was the first program cell death protein-1 (PD-1) inhibitor approved for malignant melanoma. ${ }^{3}$ In July 2015, it was approved as a second-line treatment of squamous cell carcinoma of the lung. ${ }^{4}$ Since then, the use of nivolumab has extended to other malignancies such as head and neck cancer, renal cell carcinoma, and the list continues to expand. In lung cancer, it demonstrated superior overall survival of 9 months, compared with 6 months with docetaxel. ${ }^{4}$ Other checkpoint inhibitors such as pembrolizumab ${ }^{5}$ and atezolizumab ${ }^{6}$ were subsequently developed, and are also used in the treatment of lung cancer.

Serious potential autoimmune complications arise in up to $30 \%$ of patients treated with PD-1 inhibitors. Dermatologic toxicity is the most common immune-related adverse event in these patients. In addition to vitiligo, most common is a reticular maculopapular rash on the trunk and extremities. Other adverse events, such as photosensitivity, alopecia, xerosis, and hair color changes, are reported less frequently. ${ }^{7}$ We report here a case of rash at an unusual location (auricular and periauricular) with skin exfoliation mimicking other common skin conditions such as eczema and psoriasis.

\section{Case presentation and summary}

A 57-year-old woman with a history of cerebrovascular accident with residual left lower-leg paresis presented for acute onset expressive aphasia in the absence of other constitutional or neurological findings. Magnetic resonance imaging of the brain showed a posterior, left parietal lobe lesion of 1.6 $\mathrm{cm}$ with intralesional hemorrhage and surrounding edema suggestive of brain metastasis. The patient had a 35 pack-year history of smoking. A staging work-up with computed-tomographic (CT) scans showed a spiculated enhancing nodule in the superior segment of the right lower lobe plus mediastinal adenopathy.

The patient underwent a CT-guided core biopsy of the spiculated nodule, which was found to be consistent with adenocarcinoma of the lung. It was negative for $E G F R$ mutation or $A L K$ rearrangement. She received stereotactic radiosurgery to the left posterior parietal lesion, and after completion of radiation, was started on systemic chemotherapy with cisplatin plus pemetrexed for adenocarcinoma of the lung. She received 4 cycles of chemotherapy. Repeat imaging with a PET-CT showed interval increase of the mediastinal hypermetabolic lymphadenopathy with new hypermetabolic pretracheal lymph nodes and interval development of multiple liver metastases in the right and left lobes of the liver (Figure 1). She was started on second-line therapy with nivolumab at a dose of $240 \mathrm{mg}$ every 2 weeks. The treatment was complicated initially by new onset grade 2 papular pruritic rash after cycle 2 of therapy. The rash involved the upper and lower extremities, sparing the palms, soles, trunk, abdomen, and the back. It resolved with treatment delay and topical steroids.

The patient resumed treatment with nivolumab after complete resolution of the rash. However, she developed grade 2 nephritis after cycle 5 with a creatinine level of $1.98 \mathrm{mg} / \mathrm{dL}$ (reference range, 0.6$1.2 \mathrm{mg} / \mathrm{dL}$ ). This was resolved after treatment with oral prednisone, at a starting dose of $1 \mathrm{mg} / \mathrm{kg}$ and tapered over 4 weeks. PET CT scans obtained after cycles 5 and 11 showed no metabolic activity in the mediastinum or the liver and markedly decreased uptake in the right lower lobe nodule, down to an

Accepted for publication February 14, 2018. Correspondence: Reinhold Munker, MD; rmunker@tulane.edu or gtanios@ tulane.edu. Disclosures: The authors report no disclosures or conflicts of interest. JCSO 2018;16(3):e159-e162. (O2018 Frontline Medical Communications. doi: https://doi.org/10.12788/jcso.0403 

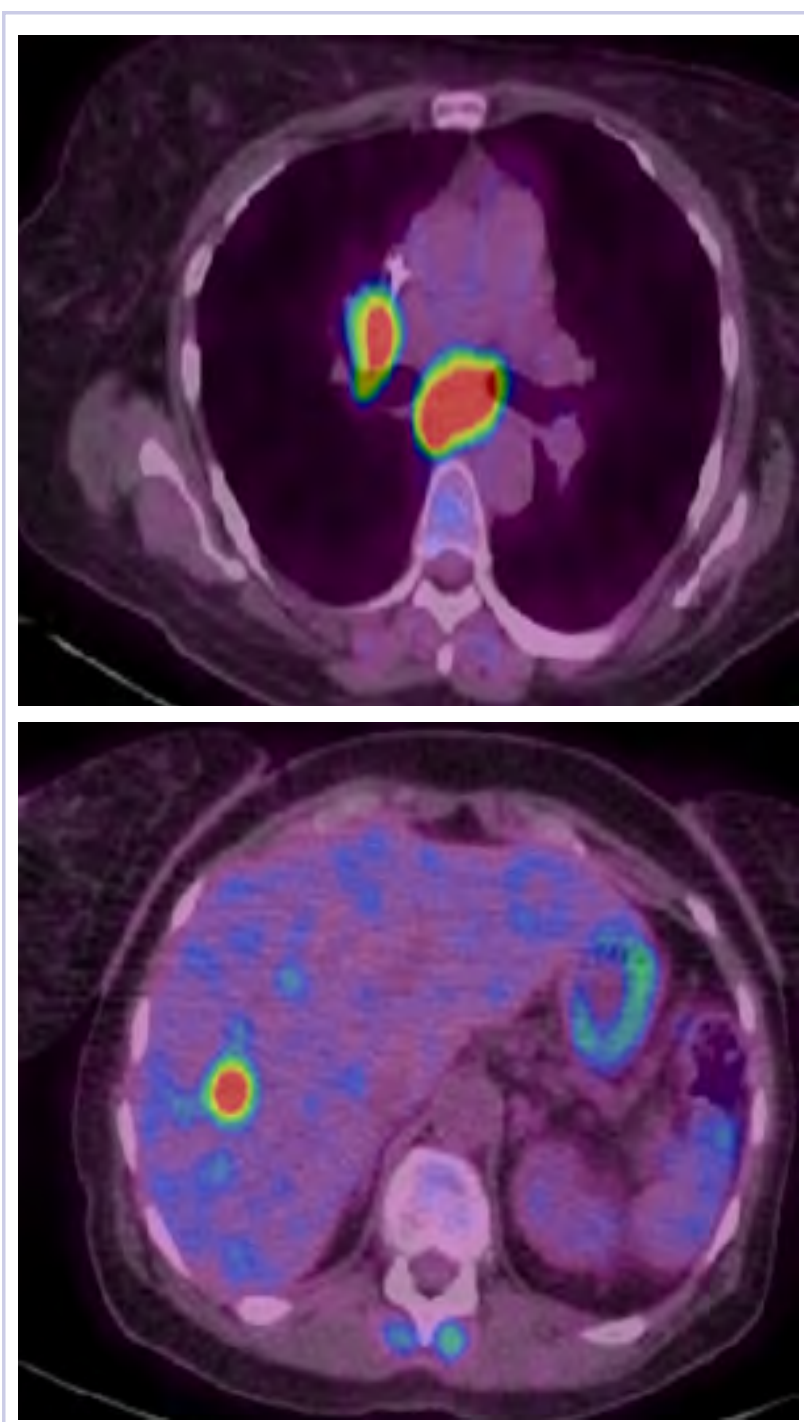

FIGURE 1 PET-CT of $\mathbf{A}$, chest, right hilar soft tissue mass, SUV 9.2, plus subcarinal node (SUV 12.8), and B, abdomen, with hypermetabolic focus in liver.

SUV of 1.7 with no new nodules. An MRI of the brain was stable (Figure 2).

After cycle 16 of nivolumab, the patient developed a severe eczematous rash with excoriations at the base of both ears involving the periauricular and auricular areas bilaterally (Figure 3). She had a normal otoscopy exam, however, she also developed a maculopapular rash over the anterior abdomen (not shown). After failure of topical steroids and 1 week of oral antibiotics, she was started on prednisone $1 \mathrm{mg} / \mathrm{kg}$ daily. She was seen after 1 week and had a significant response to the treatment, with resolution of the periauricular and auricular eczematous lesions as well as the abdominal rash (Figure 4). She completed 4 weeks of steroid therapy on a tapering schedule. Treatment with nivolumab was resumed afterward with no adverse
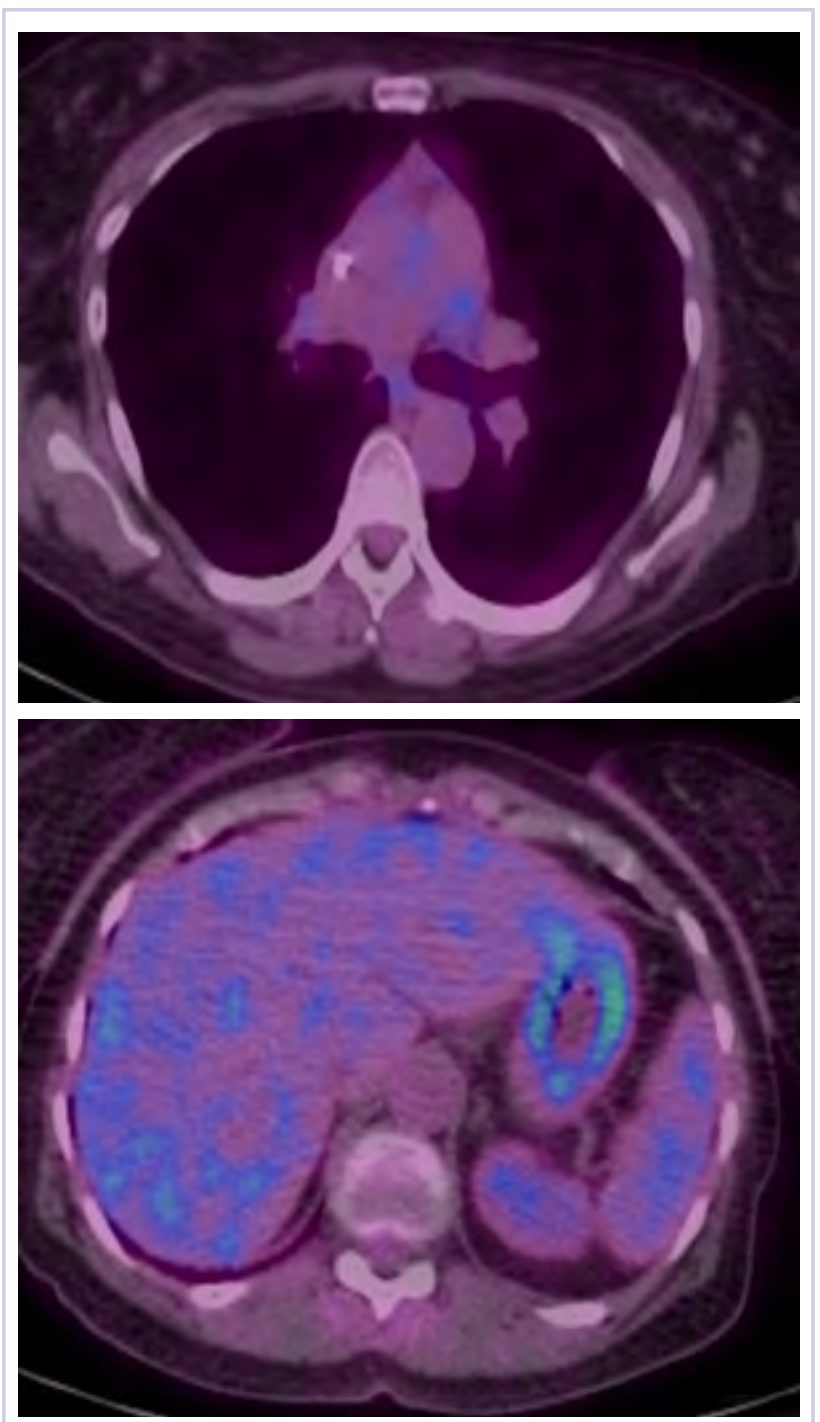

FIGURE 2 PET-CT of $\mathbf{A}$, chest showing resolution of hypermetabolic lesions, and $\mathbf{B}$, resolution of hypermetabolic lesions, physiologic uptake of FDG in liver.

autoimmune complications. At her last visit (25 months after initiating a PD-1 inhibitor), there was no clinical or radiologic evidence of lung cancer nor any of autoimmune adverse effects.

\section{Discussion}

Among multiple autoimmune complications, dermatologic toxicity is the most common immune-related adverse event, occuring in about $30 \%$ to $40 \%$ of patients ${ }^{7,8}$ and with an average onset of 3-4 weeks after initiating treatment with checkpoint inhibitors. ${ }^{9}$ In addition to vitiligo, the most common type of rash described is a reticular maculopapular rash on the trunk and extremities. ${ }^{10}$ Other findings, such as photosensitivity, alopecia, xerosis, and hair color changes, have been reported in smaller numbers. Skin exfoliation, as seen 

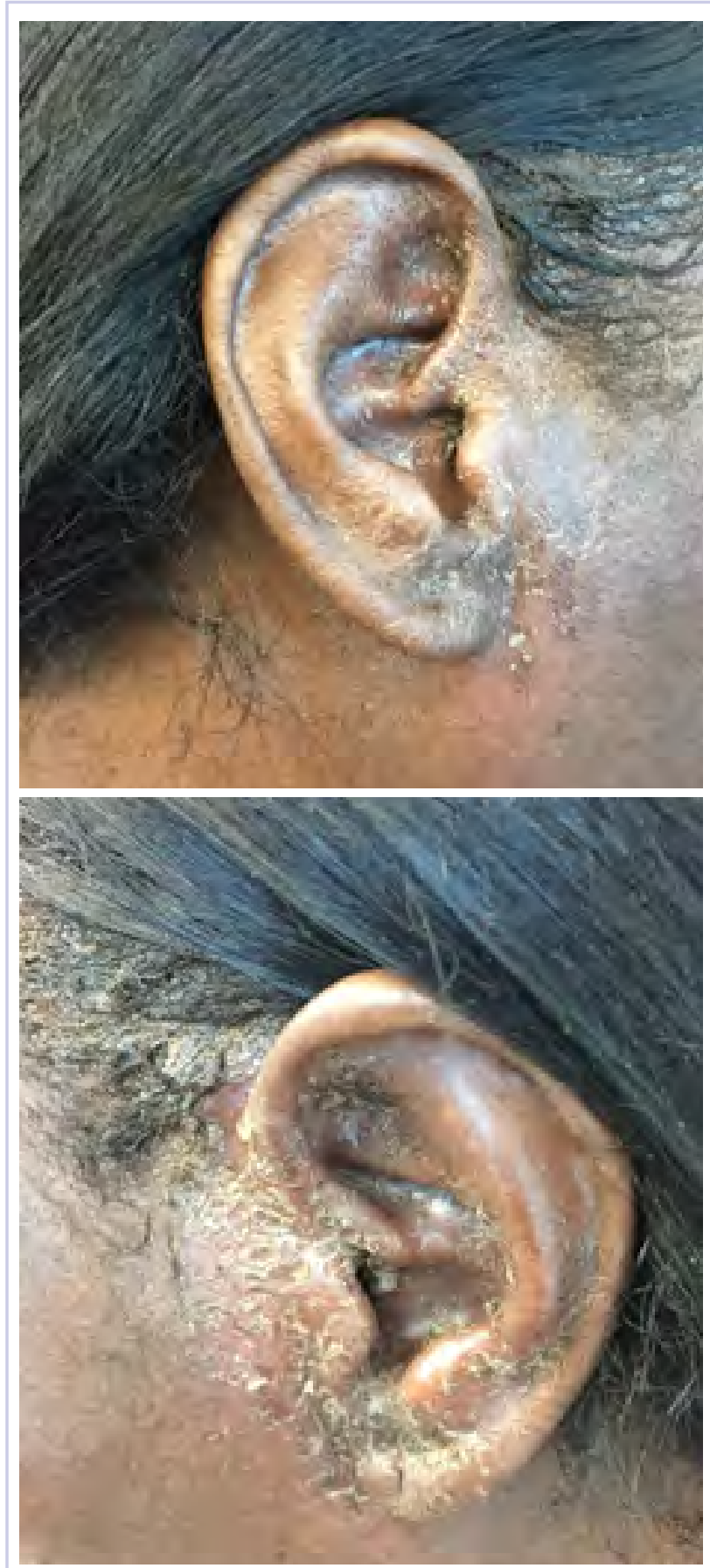

FIGURE 3 Severe eczematous rash with skin excoriations and irritation at the base involving periauricular areas bilaterally (before treatment)

in the present case, has been reported in fewer than $1 \%$ of the cases. ${ }^{4}$ Perivascular lymphocytic infiltrates extending deep into the dermis are most likely to be seen if the lesions are biopsied. Both the location of the rash in our patient and its relapsing nature are rare and make it more interesting as it presents a diagnostic dilemma for treating physicians.

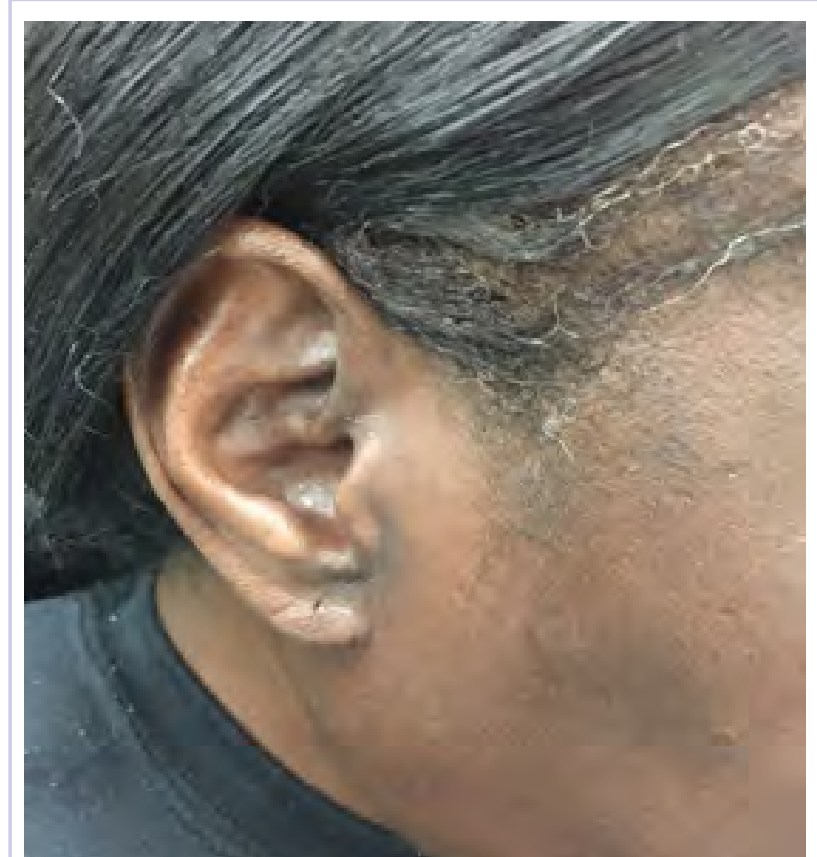

FIGURE 4 Resolution of the rash after 1 week of treatment with steroids.

Ear, nose, and throat surgeons are more likely to encounter such a complication with the expanded use of PD-1 and PD-ligand 1 inhibitors in advanced head and neck cancers. The differential diagnosis includes localized eczema, psoriatic rash, skin infection, or an autoimmune phenomenon.

The location of the rash was also of concern because there have been reports of autoimmune inner-ear disease related to immunotherapy. ${ }^{11}$ After the failure of treatment with empiric antibiotics and topical steroids, in addition to the development of a new rash on her abdomen, we concluded that this case might represent an unusual autoimmune skin complication. The resolution of the skin lesions in both locations (the ears and the abdomen) with the oral steroid therapy, supported our suspected diagnosis of autoimmune dermatitis.

It is essential that these complications are detected early and misdiagnosis is avoided because timely treatment with steroids will prevent progression to more severe problems such as Steven-Johnson syndrome, toxic epidermal necrolysis,${ }^{12}$ or extension into the inner ear. ${ }^{11}$

This case is part of a growing spectrum of other unusual cases seen with immunotherapy treatment, such as erythema nodosum-like reactions, ${ }^{13}$ bullous dermatitis, ${ }^{14}$ and psoriasiform eruptions. ${ }^{15}$ It highlights the need for an awareness of expanding dermatologic complications from immunotherapy beyond the reported common manifestations. Established guidelines and algorithms for the management of immunerelated dermatologic toxicity are available to assist the physician in treatment (Table 1). ${ }^{16}$ Skin biopsy should be considered if the diagnosis remains uncertain, although starting 
empiric treatment with steroids is a widely acceptable approach. Reassessing the skin rash in 48 hours to 1 week after treatment initiation is crucial because steroid-refractory cases will need additional immunosuppression. Early termination of steroids is associated with higher recurrence rate, therefore tapering steroids over 4 weeks is highly recommended before resuming treatment with checkpoint inhibitors.

In summary, increased awareness among health care professionals of the common and unusual complications of immunotherapy agents is important and essential in patient care. In addition to oncologists, head and neck surgeons, pulmonologists, urologists, dermatologists, and general internists will encounter patients with immunotherapy-related complications. Patient education should be emphasized to ensure prompt investigation and treatment of complications. Finally, it is not yet clear whether the development of autoimmune reactions predicts disease response to treatment. In a series of 134 patients with lung cancer, the occurrence of autoimmune adverse events correlated with improved survival. ${ }^{17}$ More research is needed to identify prognostic and predictive biomarkers for response to immunotherapy.

\section{Conclusion}

This pattern of autoimmune dermatitis localizing to the ears is rare ( $<1 \%$ of cases of dermatitis). Nevertheless, it raises the awareness for dermatologic complications of immunotherapy beyond the classical reported manifestations. Prompt diagnosis and treatment is essential to avoid serious complications such as Steven-Johnson syndrome, toxic epidermal necrolysis, and potentially damage to the inner ear.

\section{References}

1.Torre LA, Bray F, Siegel RL, Ferlay J, Lortet-Tieulent J, Jemal A. Global cancer statistics, 2012. CA Cancer J Clin. 2015;65(2):87-108.

2. Goldstraw P, Chansky K, Crowley J, et al. The IASLC Lung Cancer Staging Project: proposals for revision of the TNM stage groupings in the forthcoming (Eighth) edition of the TNM classification for lung cancer. J Thorac Oncol. 2016;11:39-51.

3. Robert C, Long GV, Brady B, et al. Nivolumab in previously untreated melanoma without $B R A F$ mutation. $\mathrm{N}$ Engl J Med. 2015;372:320-330.

4. Brahmer J, Reckamp KL, Baas P, et al. Nivolumab versus docetaxel in advanced squamous-cell non-small-cell lung cancer. N Engl J Med. 2015;373:123-135.

5. Reck M, Rodriguez-Abreu D, Robinson AG, et al. Pembrolizumab versus chemo-therapy for PD- L1- positive non-small-cell lung cancer. N Engl J Med. 2016;375:1823- 1833

6. Rittmeyer A, Barlesi F, Waterkamp D, et al. Atezolizumab versus docetaxel in patients with previously treated non-small-cell lung cancer (OAK): a phase 3, open-label, multicentre randomised controlled trial. Lancet. 2017;389:255-265.

7. Collins LK, Chapman MS, Carter JB, Samie FH. Cutaneous adverse events of the immune checkpoint inhibitors. Curr Prob Cancer. 2017;41:125-128.

8. Naidoo J, Page DB, Li BT, et al. Toxicities of the anti-PD-1 and anti-PD-L1 immune checkpoint antibodies. Ann Oncol. 2015;26(12):2375.

9. Weber JS, Kähler KC, Hauschild A. Management of immune-related adverse events and kinetics of response with ipilimumab. J Clin Oncol. 2012;30(21):2691-2697.

TABLE 1 Management of skin toxicity of checkpoint inhibitors ${ }^{\circ}$

\section{Grade, manifestation}

Grade 1 Skin rash, with or without pruritus, $<10 \%$ of BSA

$\begin{aligned} & \text { potency, } \pm \text { topical or oral antihista- } \\ & \text { mines for itching } \\ & \text { Continue CPI }\end{aligned}$

Grade 2

Skin rash, 10\%-30\%

of BSA

- Continue supportive management as above

- Topical steroids or lotion of moderate potency, \pm topical or oral antihistamines for itching

- Continue $\mathrm{CPI}$

\begin{tabular}{|c|c|}
\hline $\begin{array}{l}\text { Grade } 3 \\
\text { Skin rash }>30 \% \\
\text { of BSA, OR grade } \\
2 \text { with significant } \\
\text { symptoms }\end{array}$ & $\begin{array}{l}\text { - Hold CPI } \\
\text { Initiate steroids at } 0.5-1 \mathrm{mg} / \mathrm{kg} \\
\text { prednisone equivalent, for 3-7 } \\
\text { days, then taper over } 1-2 \text { weeks, in } \\
\text { severe cases IV, then transition to } \\
\text { oral, taper over } 2-4 \text { weeks } \\
\text { - Restart CPI if rash returns to grade } 1 \\
\text { or mild grade } 2 \text {, discuss with patient }\end{array}$ \\
\hline $\begin{array}{l}\text { Grade } 4 \\
\text { Skin sloughing }>30 \% \text {, } \\
\text { with associated } \\
\text { symptoms (erythema, } \\
\text { purpura, epidermal } \\
\text { detachment) }\end{array}$ & $\begin{array}{l}\text { - Start IV methylprednisolone 1-2 } \\
\mathrm{mg} / \mathrm{kg} \text {, get urgent consultation } \\
\text { with dermatologist } \\
\text { - Discontinue CPI }\end{array}$ \\
\hline
\end{tabular}

BSA, body surface area; CPI, checkpoint inhibitors

aModified from Haanen et $\mathrm{al}^{16}$
10. Belum VR, Benhuri B, Postow MA, et al. Characterisation and management of dermatologic adverse events to agents targeting the PD-1 receptor. Eur J Cancer. 2016;60:12-25.

11. Zibelman M, Pollak N, Olszanski AJ. Autoimmune inner ear disease in a melanoma patient treated with pembrolizumab. J Immunother Cancer. 2016;4:8.

12. Nayar N, Briscoe K, Penas PF. Toxic epidermal necrolysis-like reaction with severe satellite cell necrosis associated with nivolumab in a patient with ipilimumab refractory metastatic melanoma. J Immunother. 2016;39(3):149-152.

13. Tetzlaff MT, Jazaeri AA, Torres-Cabala CA, et al. Erythema nodosum-like panniculitis mimicking disease recurrence: a novel toxicity from immune checkpoint blockade therapy - report of 2 patients. J Cutan Pathol. 2017;44(12):1080-1086.

14. Naidoo J, Schindler K, Querfeld C, et al. Autoimmune bullous skin disorders with immune checkpoint inhibitors targeting PD-1 and PD-L1. Cancer Immunol Res. 2016;4(5):383-389.

15. Ohtsuka M, Miura T, Mori T, Ishikawa M, Yamamoto T. Occurrence of psoriasiform eruption during nivolumab therapy for primary oral mucosal melanoma. JAMA Dermatol. 2015;151(7):797-799.

16. Haanen JBAG, Carbonnel F, Robert C, et al; ESMO Guidelines Committee. Management of toxicities from immunotherapy: ESMO clinical practice guidelines for diagnosis, treatment and follow-up. Ann Oncol. 2017;28(suppl 4):iv119-iv142.

17. Haratani K, Hayashi H, Chiba Y, et al. Association of immunerelated adverse events with nivolumab efficacy in non-small-cell lung cancer. JAMA Oncol. 2018;4(3):374-378. 